\title{
Forward Osmosis: Commercialization and Acceptance Considerations
}

\author{
Peter Nasr* \\ Center for Sustainable Development, The American University in Cairo, Cairo, Egypt
}

Submission: February 26, 2017; Published: March 21, 2018

*Corresponding author: Peter Nasr, Center for Sustainable Development, The American University in Cairo, Cairo, Egypt, Email: pnasr@aucegypt.edu

Keywords: Forward osmosis; Desalination; Thermodynamic

Abbreviations: FO: Forward Osmosis; O\&G: Oil \& Gas; WDR: Water Desalination Report; MBR: Membrane Bioreactor; HTI: Hydration Technology Innovations

\section{Introduction}

Until recently, forward osmosis (FO) has been primarily an academic pursuit. Significant scientific work and development have further advanced the technology, opened new applications, and improved both the financial and technical merits of the process. However, limited publicly available information on real world applications, cost data, and experience with engineered applications of FO has limited market acceptance and penetration. FO is now growing rapidly due to recent technical innovations, better suited applications, increased demand for novel solutions for difficult waters, and increased exposure.

This work seeks to give an expert's perspective on the progress made, and remaining work to drive the FO process toward greater acceptance. Throughout this investigation it is assumed the reader has a general understanding of osmotic processes. For simplicity, all osmotically driven membrane processes are referred to simply as FO.

\section{FO in the Minds of the Public}

F0 has long had a fragmented reputation, with advocates on one side and opponents on the other. Relatively little the general public and even water industry insiders know about FO feeds this cycle. As such, each new article on FO claims the process as either a "break-through" or just another example of "too-goodto-be-true". Those working in FO know the reality is somewhere in the middle. An excellent example is the years of FO being marketed as an energy efficient alternative to RO desalination, and the inevitable blowback from sceptics who point to the thermodynamic minimums for desalination.

One bright spot in this information duality are industry specific articles. Water Desalination Report in April of 2013 ran two weekly issues completely devoted to various FO processes, the state of the technology and market, and identified the various players. In addition, FO news is often presented and very well covered in WDR (Water Desalination Report, Vol 49 Nos. 14-15, April, 2013). Increased coverage from a variety of sources will serve to educate potential clients on the benefits of FO.

\section{F0 markets}

One benefit of FO is a relatively large and varied market potential. The main markets FO can and is having an impact in include Oil \& Gas (O \& G), Industrial, Food and Beverage, and Municipal. Across all markets, FO competes best where either difficult waters are being treated or there is an existing waste energy source that can be harnessed by various FO processes (chemical or thermal gradients).

In the $O \& G$ and industrial markets, uses for the FO processes fall into either waste minimization or resource recovery/product concentration (or both). A thermal FO process is used by Oasys Water in Texas to treat produced water in a waste minimization scheme. The process is able to utilize waste heat to reduce the volume of produced water by $60 \%$, minimizing the waste stream. Additionally, the resultant streams from the process illustrate how, when separated, waste can become a resource; the $700 \mathrm{ppm}$ freshwater stream and the $240,000 \mathrm{ppm}$ brine stream can both be reused for other purposes (Oasys Water, 2018). Another industrial market example is the use of FO+RO by Porifera for treatment of manufacturing wastewater for high purity reuse and near ZLD. While conventional membrane technologies fouled rapidly on the wastewater (COD, oil, grease, surfactants), the $\mathrm{FO}+\mathrm{RO}$ system was able to recover $80 \%$ of the water and achieve high purity targets, which in this case could not have been met with a thermal process [1]

The food and beverage market likewise has several different areas where FO can be brought to bear including food product 
concentration, direct-to-consumer products, and process wastewater treatment. Food products could potentially be concentrated with FO utilizing food based draw solutions. Such an application would allow the concentration of food without applying heat and/or pressure. Hydration Technology Innovations (HTI) also markets direct-to-consumer hydration products utilizing FO membrane bags and a nutrient draw solution. These products are marketed in the outdoor and emergency response sectors [2]. Process wastewater treatment applications are similar to the municipal market discussed below.

As of yet, there is very little penetration of FO into the municipal market. However, potential applications include water treatment, wastewater treatment, and perhaps most likely, water reuse. While FO could certainly be applied to water treatment applications it would be difficult to compete cost effectively with conventional treatment technologies unless the water is difficult for conventional technologies to treat. This in large part includes desalination, although difficult to treat waters or areas with an abundance of low grade waste energy could compete. Modern Water has completed and operated for the last several years

Table 1: A partial cross section of the market players. the only two commercial FO desalination plants in the world (Gibraltar and Oman), and acknowledges that FO is best able to compete with conventional desalination on "challenging" waters (Modern Water, 2018). On the wastewater front, FO has been tested in a Membrane Bioreactor format (Osmotic MBR, OsMBR) [2]. These systems would prove beneficial in a system where very high quality permeate is required (OsMBR permeate to RO membranes) or where the diluted brine can be used as is (such as dilution of RO brine before discharge). The main benefits of the OsMBR are the high rejection of dissolved solids at the FO membrane and the potential to use an existing waste energy for the MBR separation [3].

The characteristics of FO include the ability to treat very difficult feed waters, and provide exceptionally clean permeate. These two characteristics position FO very well for water reuse schemes in which a very impaired source must be purified to a very high level. These schemes essentially bring the water and wastewater treatment abilities of FO together; for instance using an OsMBR to dilute seawater before desalination or a thermal FO process to purify produced water for reuse (Table 1).

\begin{tabular}{|c|c|c|c|c|}
\hline & Full Scale Plant Design & Piloting & $\begin{array}{c}\text { Membrane Design/ } \\
\text { Fabrication }\end{array}$ & Draw Solution \\
\hline Aquaporin & & & $\sqrt{ }$ & \\
\hline CDM Smith & $\sqrt{ }$ & $\sqrt{ }$ & $\sqrt{ }$ \\
\hline CSM & & $\sqrt{ }$ & $\sqrt{ }$ \\
\hline $\begin{array}{c}\text { Forward Water } \\
\text { Technologies }\end{array}$ & $\sqrt{ }$ & $\sqrt{ }$ & $\sqrt{ }$ \\
\hline HTI & & $\sqrt{ }$ & $\sqrt{ }$ \\
\hline Modern Waters & & $\sqrt{ }$ & $\sqrt{ }$ & \\
\hline Oasys Water & & $\sqrt{ }$ & & \\
\hline Porifera & & & & $\sqrt{ }$ \\
\hline Toyobo & & & & \\
\hline Trevi Systems & & & & \\
\hline
\end{tabular}

\section{Market players}

Players in the FO market have proliferated in recent years as water sources have become less conventional, processes and membranes have improved, and potential customers have become more comfortable with FO. A partial cross section of the market players is included below.

\section{Barriers to Wider Use}

While significant efforts have been made in the last few years to allow the wider use of FO, several barriers still exist. Some of these must simply be pushed through with effort and persistence. However, several of the remaining barriers can be removed through coordination of the various market players.
The largest and most difficult barrier for any new water technology is the closed, slow moving water markets run by conservative owners and engineers. Particularly in the municipal market, both owners and engineers are hesitant to use any new technology that has anything less than a long track record going back decades. The industrial market is somewhat less conservative and more willing to take a risk on a somewhat proven technology that promises to save time, money, or effort in their processes. As such, the first steps of breaking into the water market have always been piloting, industrial use, and eventual adoption by the municipal market. The FO industry is now operating a significant number of pilot systems and beginning to break into the industrial market. A recent example of this is the announcement that Oasys Water won a bid industrial 


\section{Civil Engineering Research Journal}

treatment project in China [4]. Publication and promotion of these successes will help to establish a reputation for FO.

Use of non-NSF-60/61 materials and chemicals is another barrier for wider use, at least in the potable (and thus generally municipal) water market. In many regions (including many states in the USA) the use of non-NSF certified materials and chemicals is prohibited for potable water systems. If non-NSF systems are to be used in these cases either the materials and chemicals must be certified by NSF for potable water use, or the process must be redesigned to eliminate the non-certified materials and chemicals. Similarly, some regions require regulatory approval for all new potable water treatment technologies. In these cases, extensive piloting is typically required before approval.

The proprietary nature of many of the FO systems and materials are also a barrier to use, although the MF/UF market shows that this can be overcome. It is clear that vendors and manufacturers prefer a proprietary approach for its higher margins and more flexible mechanical design, however this type of market makes designing, specifying, and bidding systems and technologies more difficult and many (mostly municipal) owners resist proprietary formats. Lastly, there is a lack of clear and consistent cost data for FO systems. Consultants and owners have a general knowledge of the cost of various conventional technologies that can be employed, but have no way of developing high level estimates for an FO system alternative. This lack of information could be combated with consistent and real world case studies highlighting the CAPEX, OPEX, and process parameters of completed pilots and full scale plants, but what is really needed is several competitively bid projects across the FO market [5].

\section{Drivers for Wider Use}

Although barriers exist, there are also significant drivers for wider use of FO across the industries discussed. These drivers generally fall into one of two categories; sole solutions to emerging problems, or efficient solutions to existing problems. For an FO system to fit an application, it must meet one of these two drivers. Situations in which FO is the sole solution to an emerging problem are relatively rare. Examples of these types of applications may include food concentration in the food and beverage industry. While there are other ways to concentrate food, it could be conceived that there are foods for which application of heat or pressure is not acceptable. Another sole solution situation is water recovery from extremely fouling or highly concentrated waters, where significant strides are being made by the various FO market players.

Many FO applications will be an efficient solution to an existing problem. An example of this is the use of waste heat for the thermal FO treatment of produced water. While conventional technology could solve the problem, FO is able to do so in a more efficient manner. It should be noted that in most of these situations, the improved efficiency comes not from consuming less energy, but from consuming energy from a waste source. An example of an application where FO truly does consume less energy could be FO dilution of seawater with wastewater before desalination. In this case, the use of FO is more efficient than separate wastewater treatment and desalination steps

\section{How to get municipal acceptance}

Municipal acceptance of new technology is much more difficult than industrial or food and beverage. Municipal owners and engineers tend to be much more conservative and want to be ensured of a long lasting, reliable, and robust system. Typically municipal owners prefer to be able to manage the system as needed, which necessitates simple and reliable operation. Another difference from the industrial market is that technologies are typically recommended by the consultant to the owner; thus, initial education and marketing should be focused on consultants. However, owners will still require significant education before they will be willing to accept a technology they are unfamiliar with. Most municipal projects are bid, and specifications require at least two (usually three) acceptable vendors. Therefore, after successfully getting specified the vendor still must out bid one or two other vendors. In rare occasions an owner and consultant may decide that a sole source specification (where only one vendor is listed) is acceptable. In this case, the vendor is not required to compete. Generally in the case of a sole source, an agreement between the owner and vendor is established before the project is bid [6].

\section{Stakeholders prospective}

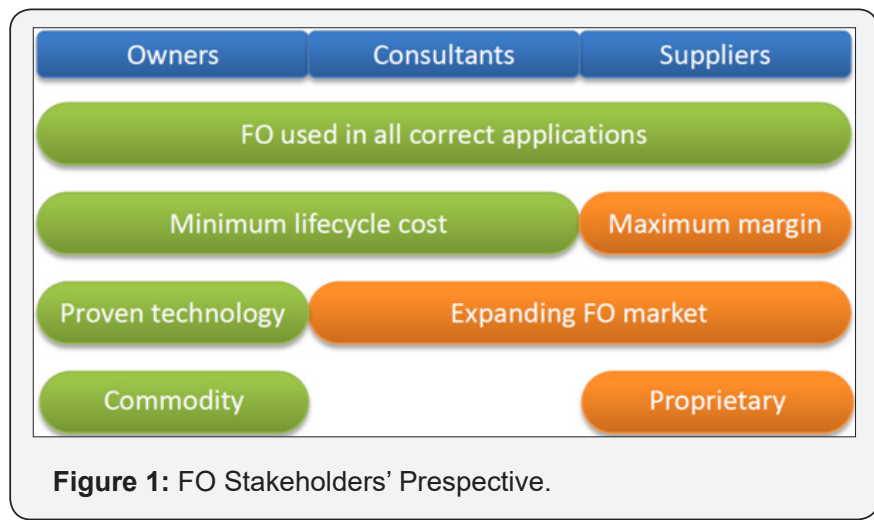

The goals of owners, consultants, and suppliers are in some cases similar and in some cases different. From the perspective of the owner, they would like a low cost, reliable system, preferably with several acceptable vendors for both initial purchase and ongoing maintenance and upgrades. The FO suppliers, on the other hand, would prefer proprietary solutions as these are less risky at bid and lock the owner into the vendor's replacement and upgrade services. Consultants tend to fall in the middle. Proprietary systems are acceptable, but they still strive for a lowest lifecycle cost solution. Regardless, all can agree that FO should be used in every correct and most efficient application (Figure 1). 


\section{Civil Engineering Research Journal}

\section{Going forward}

From a consultant's perspective, there are several short term items that would help sell the process both to other consultants and prospective clients.

Consistent defendable success stories: For each application, a success story showing the benefits, costs, and expected outcomes from use of the FO process. Preferably these would be published or presented at conferences.

Process design information: Publically available membrane or process cut sheets and/or projection software allowing the engineer to develop conceptual process values, energy demand, and sizing for an application.

Reliable cost information: Cost information as a function of membrane area, flow rate, or other independent parameter to allow budget level lifecycle cost estimation. This should include consumables and estimated membrane replacement.

Proprietary package information: Literature presenting typical integration the FO system into the overall treatment process including required supplementary equipment.

\section{References}

1. Porifera (2018) Porifera. Retrieved February 16, 2018.

2. HTI (2010) HTI Water.

3. Achilli A, Cath TY, Marchand EA, Childress AE (2009) The forward osmosis membrane bioreactor: A low fouling alternative to MBR processes. Desalination 239(1-3): 10-21.

4. Water Desalination Report (2014) Water Desalination Report (No. 32)

5. Modern Water (2018) Home - Modern Water.

6. Oasys Water (2018) Oasys Water - Home.

\section{Your next submission with Juniper Publishers} will reach you the below assets

- Quality Editorial service

- Swift Peer Review

- Reprints availability

- E-prints Service

- Manuscript Podcast for convenient understanding

- Global attainment for your research

- Manuscript accessibility in different formats

( Pdf, E-pub, Full Text, Audio)

- Unceasing customer service

Track the below URL for one-step submission https://juniperpublishers.com/online-submission.php 